\title{
A Comparison of Psychology Curriculum and Instruction: China \& America
}

\author{
Feifei Huang, Marta Garrett* \\ University of Mary Hardin-Baylor, TX, USA
}

Copyright $@ 2015$ Horizon Research Publishing All rights reserved.

\begin{abstract}
As China becomes a more international platform, studying abroad is an increasingly popular choice for Chinese students. Business is the most popular major Chinese students choose when studying abroad but a growing number of Chinese students are interested in psychology. To ensure a meaningful experience, it is essential to understand the differences of curriculum and instruction between Chinese universities and American universities. As is the case with many international students in American universities, Chinese students often face language issues. However, they might also encounter other issues related to the difference between American and Chinese culture. These cultural differences can add pressures to many Chinese students, which can negatively impact their academic progress.
\end{abstract}

Keywords Curriculum, Instruction, Psychology, China, America

\section{General Background}

Studying abroad is becoming a common choice for many Chinese students. Because of the high quality of American education, America remains China's top pick to study abroad. "The US still takes the lead as the No. 1 country choice to study abroad for Chinese students. The percentage is 9.5 percent higher than that of the UK, the second most popular destination." [14, para. 7]. After initially being developed in Europe, psychology and the greater helping professions have evolved into a well-developed profession in the West with American universities offering a wide variety of undergraduate and graduate educational opportunities.

\section{Differences in Chinese and American Undergraduate Psychology Curriculum}

This paper compares psychology-related curriculum at the Bachelor's and Master's level in two universities: PeKing
University in Beijing (PKU), and University of Mary Hardin-Baylor (UMHB). PeKing University is wildly considered as the "Harvard of China" (US-CHINA, 2014) based on its high reputation. University of Mary Hardin-Baylor (UMHB) is a small, private, Christian institution in Central Texas [7] selected for convenience.

\section{Similarities}

UMHB and PKU share many of the same core courses in their undergraduate psychology programs: General Psychology, Statistics, Experimental Psychology, Psychological Methods, and Assessment and Evaluation (see Table 1, Comparison of undergraduate core course requirements in psychology). Table 2 (below) lists the additional core courses that both universities require students to complete which are unrelated to the psychology major. Both require English language courses and physical education (PE) courses.

\section{Differences}

UMHB offers both a Bachelor of Arts (B.A.) in Psychology and a Bachelor of Science (B.S.) in Psychology [7], whereas PKU only provides B.S. in Psychology [3]. At PKU, students in both the clinical and non-clinical tracks are required to complete the same major core courses, whereas at UMHB there are some course differences in these two tracks. Additionally, PKU requires more psychology courses overall and significantly more coursework in the biological area (see Table 1).

Because UMHB is a religiously affiliated institution, it requires religiously-based courses like Bible study and Chapel (Table 2). In comparison, PKU requires politically based courses (e.g., political theories and history of socialism and communism). Table 2 indicates that PKU pays more attention to learning theories and math, while UMHB focuses more on cultivating students' comprehensive abilities such as art, science, and public speaking. Elective courses at PKU are all related to the student's major (psychology) such as education psychology, school psychology, psychology history, and child behavioral disorders. 
Table 1. Comparison of undergraduate core course requirements in psychology

\begin{tabular}{|c|c|c|}
\hline \multirow{3}{*}{ Courses } & Core courses for the undergraduate Psychology major & \multirow{3}{*}{$\begin{array}{c}\begin{array}{c}\text { PeKing } \\
\text { University }\end{array} \\
\text { Regular and Clinical track }\end{array}$} \\
\hline & $\begin{array}{c}\text { University of } \\
\text { Mary Hardin-Baylor }\end{array}$ & \\
\hline & Clinical track & \\
\hline General Psychology & $\sqrt{ }$ & $\sqrt{ }$ \\
\hline Statistics & $\sqrt{ }$ & $\sqrt{ }$ \\
\hline Psychological Methods & $\sqrt{ }$ & $\sqrt{ }$ \\
\hline History \& Systems of Psychology & $\sqrt{ }$ & \\
\hline Experimental Psychology & $\sqrt{ }$ & $\checkmark$ (Two courses) \\
\hline $\begin{array}{c}\text { Professions in } \\
\text { Clinical Psychology }\end{array}$ & $\checkmark$ & $\begin{array}{l}\checkmark \text { (Organization } \\
\& \text { Management) }\end{array}$ \\
\hline Developmental Psychology & $\sqrt{ }$ & $\sqrt{ }$ \\
\hline Abnormal Psychology & $\sqrt{ }$ & \\
\hline Psychology of Personality & $\sqrt{ }$ & \\
\hline Social Psychology & & $\sqrt{ }$ \\
\hline $\begin{array}{l}\text { Assessment \& } \\
\text { Evaluation } \\
\end{array}$ & $\checkmark$ Senior Evaluation & $\checkmark$ \\
\hline CNS Anatomy & & $\checkmark$ \\
\hline Biological Psychology & & $\sqrt{ }$ \\
\hline Biology & Science is generally required as a non-major course in American universities & $\checkmark$ \\
\hline Cognitive Psychology & & $\sqrt{ }$ \\
\hline Abnormal Psychology & & $\checkmark$ \\
\hline Upper-level Electives & $\sqrt{ }$ (Three courses) & \\
\hline
\end{tabular}

Table 2. Comparison of general education courses at the bachelor's degree level

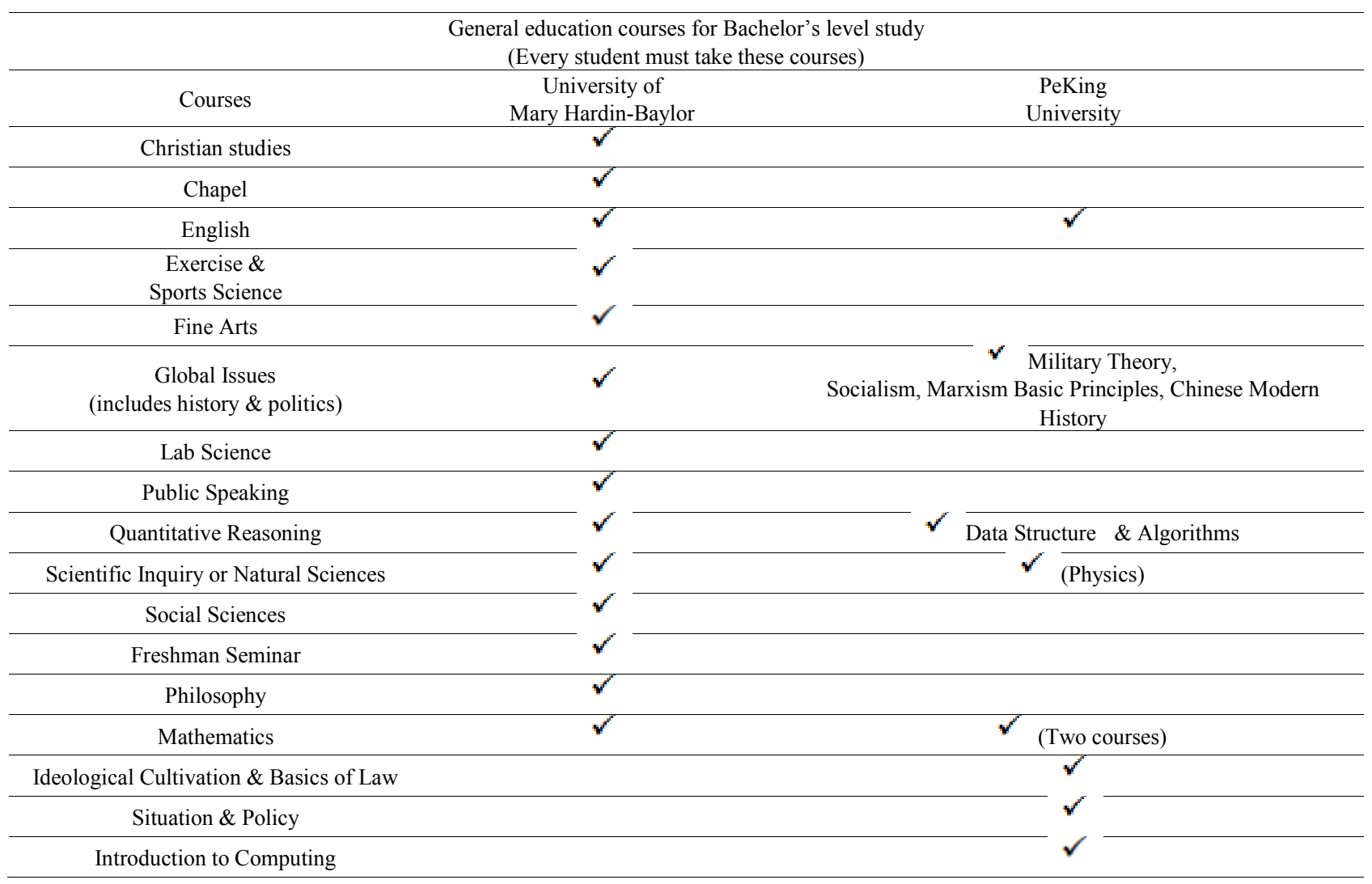




\section{Cultural Expectations at the Undergraduate Level}

Chinese universities typically do not require much homework and often do not have rigorous requirements for undergraduate students. Chinese undergraduate educational programs more commonly rely more heavily on final exams and a large thesis-type paper. By comparison, students in American undergraduate programs often are required to read textbooks and take weekly quizzes over each chapter. They are more likely to have multiple paper assignments, group discussions, presentations, and outside assignments such as interviews and observations.

\section{Comparison of Graduate Level Educational Requirements}

The larger psychological/helping professional field has evolved and developed in the last several decades and has now split into several closely related professions in the United States: Counseling, Psychology, Social Work, and Marriage and Family Therapy $[1,6]$. Each of these individual professions are now licensed and credentialed but all prepare graduates for related career $[1,6]$. State licensure for psychology and the psychologically-based professions varies by state across the U.S., but in all U.S. states, licensure for individuals to practice therapy or psychologically based services requires a minimum of a graduate-level training program with a supervised internship [1]. In the United States, the master's level degree accounts for the majority of professionals practicing in the clinical helping fields today
[1]. Table 3 below demonstrates the variance in graduate programs offered and the associated licensure [1].

In the United States, licensure for counselors is at the master's degree level while licensure for psychologists is at the doctoral level [6]. While some states may widely differentiate between the two credentials in their Scope of Practice laws, in the state of Texas, the only difference beyond the ability to use the title of "psychologist" is that Texas law allows licensed psychologists to administer and score a wider variety of psychological assessments [6] see also [9]. The UMHB graduate program focuses on training clinical practitioners to sit for state licensure as Licensed Professional Counselors (LPCs). This program requires 60 semester credits (nearly three years to complete) and includes a three semester clinical training sequence [4]. The Clinical Mental health Counseling graduate program at UMHB is nationally accredited by the Council for Accreditation of Counseling and Related Educational Programs [2]. This program prepares graduates in counseling for licensure for independent practice as LPCs [10].

All educational programs in Chinese universities are accredited by Ministry of Education of the People's Republic of China [12]. PKU's masters-level program requires 36 graduate credits to complete and focuses on training both practitioners and educators for teaching practice. Additionally, PKU requires students to complete a lengthy thesis or dissertation for graduation. Then lengthy paper should be accepted for publication before defense [3]. See Table 4 below for a comparison of the requirements for these two graduate level counseling and psychology programs.

Table 3. Common American graduate level training and associated licensure

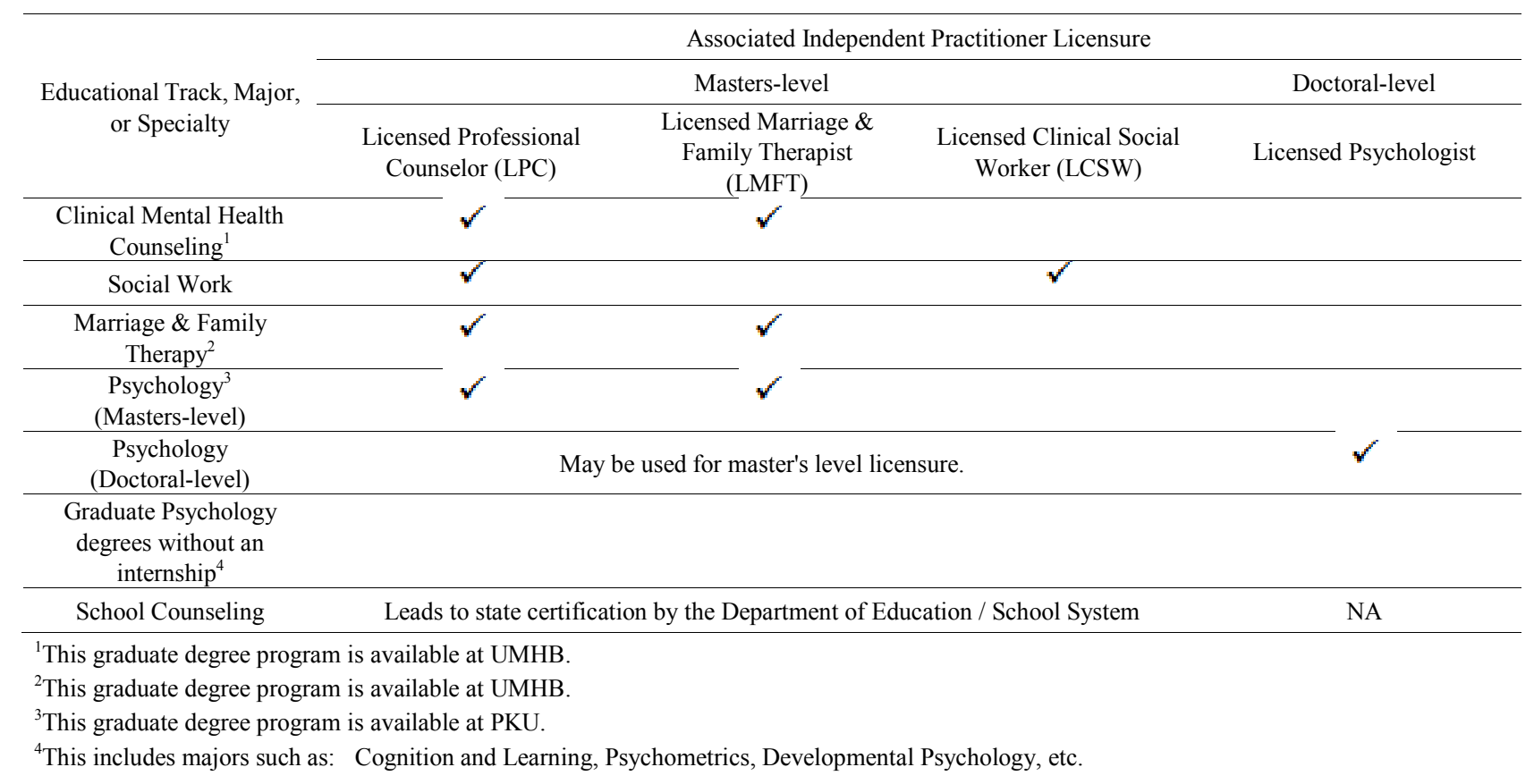


Table 4. Comparison of the core requirements at the graduate level

\begin{tabular}{|c|c|c|c|}
\hline & Requirements & $\begin{array}{c}\text { UMHB } \\
\text { Counseling }\end{array}$ & $\begin{array}{c}\text { PKU } \\
\text { Psychology }\end{array}$ \\
\hline \multirow{16}{*}{ Coursework } & Career Counseling & $\checkmark$ & \\
\hline & Professional Orientation \& Ethics & $\sqrt{ }$ (Two courses) & Elective \\
\hline & Human Development & $\checkmark$ & $\checkmark$ \\
\hline & Group Counseling & $\checkmark$ & Elective \\
\hline & Psychopathology & $\checkmark \quad$ (Two courses) & \\
\hline & Theories of Counseling & $\checkmark$ & \\
\hline & Cultural Diversity & $\checkmark$ & Elective \\
\hline & Research \& Statistical Methods & $\sqrt{ }$ & $\sqrt{\text { (Two courses) }}$ \\
\hline & Trends in Psychological Research & & $\checkmark$ \\
\hline & Cognitive Neuroscience & & $\checkmark$ \\
\hline & Applied \& skills courses & $\checkmark \quad$ (Two courses) & $\checkmark$ \\
\hline & Trauma \& Crisis Counseling & $\checkmark$ & \\
\hline & Substance Abuse \& Psychopharmacology & $\checkmark$ & \\
\hline & Marriage \& Family Theories & $\checkmark$ & Elective \\
\hline & Assessment & $\sqrt{ }$ & \\
\hline & Elective(s) & $\checkmark$ (One course) & (Seven courses) \\
\hline \multirow{2}{*}{ Practice } & Clinical Internship & $\sqrt{ }$ (Three semesters) & Elective \\
\hline & Teaching Internship & & $\checkmark$ \\
\hline
\end{tabular}

Table 5. Graduate level elective courses at UMHB and PKU

\begin{tabular}{|c|c|c|}
\hline \multicolumn{3}{|c|}{ Choices for elective courses (not already listed above) } \\
\hline \multirow{2}{*}{ Courses } & $\begin{array}{c}\text { University of } \\
\text { Mary Hardin-Baylor }\end{array}$ & $\begin{array}{c}\text { PeKing } \\
\text { University }\end{array}$ \\
\hline & $\begin{array}{l}\text { Counseling - choice of only one elective } \\
\text { course }\end{array}$ & Psychology - 14 hours elective courses \\
\hline Reading and Discussion & $\checkmark$ & $\checkmark$ \\
\hline Experiment and Research & $\checkmark \quad$ (Optional thesis) & $\sqrt{ }$ \\
\hline Human Resource Management & & $\checkmark$ \\
\hline $\begin{array}{c}\text { Seminar on FMRI } \begin{array}{c}\text { (Functional Magnetic Resonance } \\
\text { Imaging) }\end{array} \\
\end{array}$ & & $\checkmark$ \\
\hline Neuropsychology & & $\checkmark$ \\
\hline Research Methods on Indigenous Psychology & & $\sqrt{ }$ \\
\hline Cognitive Behavioral Therapy & & $\sqrt{ }$ \\
\hline Brief/Solution Focused Therapy & $\checkmark$ & \\
\hline School Counseling & & $\sqrt{ }$ \\
\hline Brain and Immunity & & $\sqrt{ }$ \\
\hline Brain and Computer & & $\sqrt{ }$ \\
\hline Human Sexuality & $\checkmark$ & \\
\hline Play Therapy & $\sqrt{ }$ & \\
\hline Expressive Arts Therapies & $\checkmark$ & \\
\hline Psychology of Language & & $\sqrt{ }$ \\
\hline Personnel Assessment \& Selection & & $\sqrt{ }$ \\
\hline Personality \& Social Psychology & & $\sqrt{ }$ \\
\hline Supervision / Supervision Practice & $\checkmark$ & $\checkmark$ \\
\hline
\end{tabular}

\section{Similarities}

At the graduate level, all compulsory courses required in both of these institutions are counseling/psychology related. These graduate level courses tend to be more skill-based than courses at the undergraduate level, and focus on teaching students to use clinical skills in counseling or analytical skills in research (see Tables 1 and 4).

\section{Differences}

Similar to preparation at the undergraduate level, PKU's required courses have more emphasis on science and research than does the UMHB graduate counseling program (see Tables 4 and 5). Tables 4 and 5 further illustrate some differences in the choice of and use of electives. UMHB allows only one elective course at the graduate level. PKU 
has a larger number of elective whereas; however, several of the elective course areas of the PKU program are required at UMHB.

Due to strict standards set by the national accrediting body and Texas state laws related to licensure, the UMHB coursework is far less flexible $[2,10]$.

\section{Cultural Expectations in Graduate School}

After graduating from a counseling program in the United States, all state laws require graduates to formally apply and pass a national licensure examination (e.g., American Counseling Association [ACA], [1]; a couple of states maintain their own state license exam, but this number has dwindled in recent years). Additionally, in most states, graduates are also required to complete two to four years of clinical practice under the supervision of a fully-licensed professional (e.g., [1]. For example, in Texas, graduates applying for the LPC credential must complete 3,000 or more hours of counseling under the supervision of a specially trained Texas-approved clinical supervisor [10]. Most counseling programs in the United States no longer require a thesis at the master's level; however, American doctoral programs in counselor education and/or some fields in psychology generally do require a dissertation or lengthy written project [6]. In recent years most graduate-level practitioner training programs (like the one being described at UMHB) have moved to a standardized licensure practice exam as a comprehensive exam to ensure graduates are adequately prepared to pass the compulsory state licensure examinations [1].

The PKU master's level program being reviewed is in psychology [3]. In China, most graduate level psychology programs have both oral and written exams, and students are required to complete a lengthy written paper such as a thesis or dissertation. Chinese graduate psychology programs typically focus on research and experimental assignments and thesis or dissertation projects. Chinese master's level psychology programs usually do not provide counseling training: "China currently has a three-tier national licensing program that dates from $2002 \ldots$ [under] ...the auspices of the Central Department of Labor" [5, p. 5]. Under this system, individuals can be licensed at all three levels; however, a licensed practitioner at level two or level three must complete a government-approve course and the pass the Department of Labor examination [5]. However, "the highly coveted Level One License is reserved primarily for those who have Qualifying doctoral degrees in the fields of education, medicine, or counseling and have worked as a therapist for at least 3 years" $[5$, p. 6$]$.

\section{Cultural Learning Differences}

American and Chinese education models differ significantly from each other as do these two groups' cultural styles as they relate to education. As described in the comparison of curriculum above, the American educational system seems to value students' comprehensive abilities (including exposure to art and other cultural aspects), while Chinese education tends to focus on scientifically-based academic learning (science, math, etc.). This may be traced back to educational at the high school level and the differences in focus in the educational system that prepares students for university level work. In China high schools the majority of students' time and focus is on the major courses such as Chinese, Math, and English. These courses make up the vast majority of the Chinese students' high school life, which overall is often seen as very serious and stressful. In contrast, American high schools often focus on developing the entire person of the student (with a significant emphasis on sporting events, social events, and other culture-specific activities).

Therefore, this differing focus at the high school level may set Chinese students up for a different experience at the university level. When Chinese students arrive in university, they expect to spend more time doing what they think they missed in high school. Consequently, cutting classes, cheating on exams, and not listening to teachers in class are common behaviors in most Chinese universities. Additionally, Chinese students seldom ask questions of university professors. Chinese students are enculturated to following teachers' instructions and expect Chinese teachers to tell them what to do. This dominant learning model suppresses Chinese students' curiosities. For Chinese students to be successful in the American learning culture, they will need to learn to use their critical thinking abilities and become more involved in their own academic success.

\section{Conclusions}

Chinese students should better prepare themselves before going to study abroad because it will not be as easy to study in American universities as they might think. This is even truer at the graduate level because they have now had more reinforcement of the Chinese academic culture in their undergraduate studies. All students who are thinking about studying abroad should carefully consider how this choice could potentially impact their individual career goals. This article does not intend to imply that Chinese education is lacking, rather to point out the potential limitations of Chinese education when it is used as a foundation for further study in a different educational culture such as in America. Hopefully, as the number of Chinese students who choose to study abroad continues to grow, the Chinese government will consider the need to further research these differences and consider the need to make policy and curriculum adjustments so that all Chinese students who want to study abroad will have adequate foundational experiences to ensure their academic and professional success. 


\section{REFERENCES}

[1] American Counseling Association (2011). 2011 Statistics on mental health professions. Alexandria, VA: Author. Retrieved from:

http://www.counseling.org/knowledge-center/licenure-requir ements

[2] Council for Accreditation of Counseling and Related Educational Programs. (2009). 2009 Standards. Retrieved from: http://www.cacrep.org/

[3] Department of Psychology. (2014). Psychology program instruction (Chinese version). PeKing University. Retrieved from: http://www.psy.pku.edu.cn/jwxx.php?bkgz=219

[4] Graduate Counseling Program Requirements. (2014). In 2014-2015 UMHB Graduate Catalog (p. 37). Retrieved from: http://registrar.umhb.edu/catalog

[5] Lim, S., Kim, B. K. H., Michael, R., Cai. R., \& Schock, C. K. (2010). The trajectory of Counseling in China: past, present, and future trends. Journal of Counseling \& Development, 88, 4-8.

[6] Lucas, A.A. (Ed.). (2009). Careers in Counseling and Psychology for Masters Level Graduates: A Guide to Choosing the Right Career Path. San Diego, CA: Cognella.
[7] Psychology Program Requirements. (2014). In 2014-2015 UMHB Catalog (p. 161). Retrieved from: http://registrar.umhb.edu/catalog

[8] Sun, F. (2013). Negative transfer of Chinese sentence patterns on students' English writing. Journal of Language Teaching and Research, 4(6), 1298-1302.

[9] Texas Department of State Health Services. (2014). Licensing and Regulation - Occupations Retrieved from: https://www.dshs.state.tx.us/Licensing-Occupations.shtm

[10] Texas State Board of Professional Counselors. (2014). Apply for a new license - requirements

[11] (paragraph 6). Retrieved from https://www.dshs.state.tx.us/counselor/lpc_appy.shtm

[12] The Ninth National People's Congress. (1998). Higher education Law of the people's republic of China. Ministry of Education of the People's Republic of China. Retrieved from: http://www.moe.gov.cn/publicfiles/business/htmlfiles/moe/m oe $2803 / 200905 / 48454 . h t m l$

[13] US-CHINA. (2014). Study at Peking University. US-CHINA. Retrieved from: http://chinastudentsummit.org/study-at-peking-university/

[14] Zhang, Y. (2014). US still China's top pick for study abroad. China Daily USA. Retrieved from: http://usa.chinadaily.com. cn/us/2014-01/21/content_17247652.htm 